\title{
Gênese instrumental e o fenômeno da ubiquidade na formação docente
}

\author{
Débora Valletta ${ }^{1}$, Marcus Basso ${ }^{2}$ \\ ${ }^{1,2}$ Programa de Pós-Graduação em Informática na Educação (PPGIE) - Universidade \\ Federal do Rio Grande do Sul (UFRGS) \\ Porto Alegre - RS - Brasil \\ deborah.teacher@gmail.com, mbassoeufrgs.br
}

\begin{abstract}
Resumo. Este artigo tem como objetivo apresentar os resultados obtidos na investigação de uma sequência de atividades apoiadas em tecnologias móveis e ubíqua desenvolvida com estudantes de curso de Licenciatura em Pedagogia. Neste estudo pretendeu-se investigar as possibilidades e os desafios gerados na apropriação de ferramentas utilizadas no cotidiano destes futuros pedagogos, ao qual transitam em/entre dois níveis da gênese instrumental pessoal $e$ profissional. Os dados produzidos a partir da análise experiencial dos estudantes com as ferramentas manipuladas na sala de aula foram analisados à luz da gênese instrumental de Rabardel articulados ao contexto da ubiquidade da informação. Os resultados apontam indicios de que os estudantes compreenderam os objetivos de aprendizagem para o uso de tecnologias na sala de aula.
\end{abstract}

Palavras-chave: gênese instrumental, ubiquidade, formação de professores

\section{Instrumental genesis and the phenomenon of ubiquity in teacher education}

\begin{abstract}
This article aims to present the results obtained in the research of a change of mobile mobility and mobility developed with undergraduate students in pedagogy. This study was intended to be tasks and challenges generically in the use of the daily pedagogues of their future, to transit in / between two levels of genesis personal instrumental and professional. Based on the experimental analysis of the students with tools manipulated in the classroom, the data were fundamental from the point of view of the instrumental genetics of Rabardel, articulated to the context of the ubiquity of the information. The results allow to identify the presence of evidence that the students understood the learning objectives for the use of technologies in the classroom.
\end{abstract}

Keywords: instrumental genesis, ubiquity, teacher education

\section{Introdução}

Nas últimas décadas, estudos sobre Informática na Educação (IE) têm apresentado limites e possibilidades em diferentes âmbitos como: infraestrutura, apropriação das ferramentas tecnológicas na escola, obsolescência programada, formação de recursos humanos, impacto na sociedade entre outros.

Grinkraut (2009) informa que as tecnologias da informação e comunicação (TIC) têm propiciado reflexões à sua inserção no ensino e na formação de professores. Garcia 
(1995) enfatiza que os professores precisam adequar-se o conhecimento geral da matéria às condições particulares da escola em que atua e do contexto em que os estudantes (con) vivem neste espaço educativo. Nesse sentido, o autor informa que o conhecimento sobre a comunidade escolar e sua procedência é essencial para planejar as aulas. Passos et al. (2006, p. 195) destacaram que a "[...] formação contínua, portanto, é um fenômeno que ocorre ao longo de toda a vida e que acontece de modo integrado às práticas sociais e às cotidianas escolares de cada um, ganhando intensidade e relevância em algumas delas. Entende-se neste trabalho que a formação continuada é parte do processo de desenvolvimento profissional do docente que se denota como algo contínuo, flexível e aberto (Valletta, 2015).

Em relação à IE destaca-se a preocupação com a formação inicial e/ou continuada de professores em serviço. Borges, Nichele e Menezes (2012) informam que após a realização de uma formação continuada a mudança de postura do professor é essencial para refletir sobre a sua própria prática. Por outro lado, Couto e Filho (2013, p. 12) concluíram que "o professor não abandona suas crenças, as tradições de seu grupo, as suas representações, ainda que aceite as novas ideias e informações.”. Valletta (2016) destaca o processo de gênese instrumental na formação de futuros pedagogos. Por fim, ressalta-se a reflexão contínua na formação dos pedagogos e/ou outras licenciaturas sob a perspectiva do uso de tecnologias na escola. Não se resolve a questão de formação somente pela oferta de cursos nas áreas tecnológicas. É necessário (re) pensar sobre o método de ensino e refletir sobre como estamos educando os professores que estão em serviço ou aqueles que ainda irão se formar nas universidades.

As possibilidades e os desafios para o uso de tecnologias na educação são diversos, pois, os contextos e as experiências de cada sujeito se diferem no tempo e no espaço - parte dos professores formadores foram instrumentalizados para a integração dos computadores na sala de aula antes e outros [professores] depois da chegada massiva da internet e seus serviços. As ferramentas de custo gratuito e/ou baixo custo estão cada vez mais acessíveis e disponíveis para qualquer usuário com acesso à Internet, ou seja, para crianças, adolescentes, adultos ou idosos. Tais ferramentas poderão, talvez, facilitar e potencializar o processo de ensino e aprendizagem para quaisquer perfis de usuários que utiliza um dispositivo conectado ${ }^{1}$ na internet. Porém, é preciso rever o método de ensino para o contexto contemporâneo.

Para ilustrar esse contexto massivo de informação e ferramentas deve-se compreender que hoje as acessamos [informação e ferramenta] de qualquer lugar e a qualquer momento quando estamos conectados e com o respectivo artefato adequado ${ }^{2}$. Tal evento é propiciado pela ubiquidade. Weiser (1991) destaca que a ubiquidade da informação advém por decorrência do uso dos computadores pessoais. Por outro lado, o autor ressalta que a computação ubíqua se torna invisível à medida em que as pessoas aprendem a lidar com a tecnologia no contexto em que as ferramentas são utilizadas - no espaço e tempo de cada sujeito.

Weiser (1991) desvela que ao usar os computadores ao "toque dos dedos" propicia-se um novo pensar sobre eles [os computadores], portanto, faz com que as pessoas deixem de ter "consciência" do uso do computador porque estão integrados ao ambiente em que vivemos e convivemos. Infere-se que ao considerar que cada estudante

\footnotetext{
${ }^{1}$ Usuários conectados à internet via wifi por meio de hotspots, operadoras de telefonia, no trabalho ou na residência.

${ }^{2}$ Entende-se que, as ferramentas são acessadas de acordo com o sistema operacional, tipo/modelo ou possibilidades funcionais do artefato.
}

V. $16 \mathrm{~N}^{\mathrm{o}} 1$, julho, 2018 
acessa as informações via dispositivos móveis em qualquer espaço e em qualquer tempo, a metodologia de ensino escolhida pelo professor, talvez, deva se tornar cada vez mais visível para que eles [os estudantes] aprendam. Logo, as ferramentas para o pensar serão possibilidades e desafios na reconstrução da didática de espaços de aprendizagem.

Observa-se no campo educacional que há tessituras significativas entre os estudos de um determinado tipo de tecnologia e a formação de professores. Mendes, Filho e Souza (2013, p. 173) destacaram que os professores mais velhos têm mais interesse para o uso de tecnologias na educação do que os professores mais jovens e que o estudo contribui com "[...] informações preciosas para o desenvolvimento de software educacional e para a oferta de cursos de formação docente cujos contextos devem considerar o interesse dos professores de determinadas gerações.”. Alencar et. al $(2015$, p. 3) apontaram que o uso do WhatsApp “ “[...] torna-se um grande facilitador quando necessita-se de uma ferramenta para avisos, compartilhamento de informações e um esclarecedor de dúvidas, tanto por parte dos professores, da instituição ou do aluno.". Notare e Basso (2017) discutem sobre o processo de gênese instrumental na formação de professores iniciantes articulados com uma sequência de atividades utilizando o software educacional Geogebra ${ }^{4}$.

Diante desse contexto, este estudo foi desenvolvido, com o objetivo de compreender o processo de apropriação tecnológica, da gênese instrumental pessoal para a gênese instrumental profissional, por parte dos estudantes de pedagogia à luz de Rabardel (1995), bem como a transformação do artefato em instrumento ao longo da sequência de atividades práticas e teóricas proposta em dois meses que totalizaram oito dias e trinta e duas horas-aula 5 .

Neste trabalho buscou-se observar os sujeitos durante as sequências de atividades em relação a experiência dos acadêmicos no curso de Pedagogia na apropriação tecnológica para o uso profissional em detrimento do uso pessoal de seus respectivos dispositivos móveis. Assumiu-se que, embora a teoria de Rabardel (1995) seja voltado para a formação de professores de Matemática, a transformação de artefato em instrumento denota-se, também, em estudos de outras áreas do conhecimento.

Professores de diferentes áreas, também, utilizam diversos tipos de ferramentas para apoio as suas atividades de trabalho. Portanto, os limites e as possibilidades de cada ferramenta são percebidos pelo professor a partir do uso associado à sua metodologia de ensino. Isto é, se o artefato possui características que propiciem novos contextos para a aprendizagem.

Os indicadores obtidos na pesquisa apontam que o processo da gênese instrumental pessoal para a gênese profissional remete respectivamente de uma cognição experiencial para reflexiva e, principalmente, sobre as práticas advindas dos formadores de professores que propicia atividades pedagógicas voltadas para o (re) pensar sobre a didática. Apontam também para a necessidade de se promover ações conscientes que rompam a cultura predominante de métodos convencionais de ensino nos cursos de formação inicial de professores, a qual situa a cognição reflexiva em segundo plano em relação a cognição experiencial de uso das ferramentas.

\footnotetext{
${ }^{3} \mathrm{O}$ WhatsApp é um aplicativo (app) de comunicação instantânea utilizado no mundo inteiro que possibilita a troca de mensagens por meio de textos, áudios e vídeos entre os usuários.

${ }^{4} \mathrm{O}$ Geogebra é um aplicativo de matemática dinâmica.

${ }^{5}$ Nesta instituição cada hora-aula equivale a uma hora -60 minutos.

V. $16 \mathrm{~N}^{\mathrm{o}} 1$, julho, 2018
} 


\section{Ubiquidade e Educação: ferramentas para o pensar}

O conceito de ubiquidade de acordo com Weiser (1991) está associado com os computadores que estão disponíveis entre os ambientes em que os usuários experienciam interações com os artefatos de forma imperceptível.

Santaella (2007) e Valletta (2015) discutem sobre o conceito de aprendizagem associado à ubiquidade articulando-a aos dispositivos móveis, a internet e seus serviços. A aprendizagem ubíqua é flexível, aberta e apoia-se em ferramentas que possibilitam acessar a informação a qualquer momento e em qualquer lugar.

Valletta, Grinkraut e Basso (2017) referem o uso das ferramentas para o pensar como uma possibilidade didática para trabalhar o processo de formação entre o concreto e o virtual, além de, destacarem o contexto da ubiquidade e o processo de gênese instrumental de um jogo utilizado para o desenvolvimento de competências associadas ao Coding (programação). Entretanto, em função das tecnologias emergentes, vão sendo desenvolvidas ferramentas suplementares categorizadas pelas lojas online como redes sociais como o app WhatsApp (uso pessoal), porém, os sujeitos articularam diferentes esquemas de utilização para o uso da ferramenta. Assim como o app Box Island é categorizado como educacional e para uso em programação e, em parte do discurso de alguns sujeitos propuseram utilizar o app para desenvolver habilidades de lateralidade.

\section{Aspectos metodológicos}

Este estudo tem abordagem qualitativa e de caráter exploratório. Bogdan e Biklen (1994) apresentaram que a pesquisa qualitativa destaca o enfoque da investigação no contexto natural e atenta-se aos fenômenos em toda a sua complexidade. Nesse sentido, a presente pesquisa enfatiza o entendimento dos hábitos e comportamentos dos sujeitos. Como instrumento para a coleta de dados utilizou-se a observação participante, três formulários semiestruturados online (um formulário para anotações gerais da aula, denominado de diário de bordo e outro formulário adaptado ${ }^{6}$ com questões pontuais sobre o uso das ferramentas para a triangulação dos dados e aprofundamento sob a perspectiva pessoal de cada sujeito) e no canal de comunicação instantânea e informal do grupo ${ }^{7}$. Os dados foram analisados a partir da análise textual discursiva (ATD) de Moraes e Galiazzi (2007).

O trabalho foi realizado com estudantes do curso de Pedagogia, em 4 etapas. $\mathrm{Na}$ primeira, ocorrida em março de 2018, desenvolveu-se duas aulas para que os estudantes pudessem compreender como categorizar ${ }^{8}$ os aplicativos (apps) para fins educacionais. $\mathrm{Na}$ segunda aula foi apresentado um exemplo de apps para os estudantes explorar as possibilidades de uso educativo. Na terceira foi disponibilizado um tablet para os estudantes selecionar alguns apps que pudessem ser categorizados e utilizados em atividades educacionais. Foi informado aos estudantes que, também, poderiam utilizar seus respectivos dispositivos pessoais para a pesquisa do app. E ao final de cada aula os estudantes enviaram o diário de bordo.

Alternando em momentos presenciais e virtuais, os estudantes interagiram no aplicativo WhatsApp para tirar dúvidas ou fazer comentários pontuais sobre as tarefas levantando sugestões e dúvidas.

\footnotetext{
${ }^{6}$ Ver Valletta (2015).

${ }^{7}$ Utilizou-se o aplicativo WhatsApp.

${ }^{8}$ Ver Valletta (2014).

V. $16 \mathrm{~N}^{\mathrm{o}}$ 1, julho, 2018
} 
Por fim, aplicou-se o questionário semiestruturado para compreender a relação dos hábitos e comportamentos dos acadêmicos no uso dos artefatos para o acesso à informação - como ocorre o processo de instrumentação e instrumentalização do artefato ${ }^{9}$ em detrimento da busca pela informação e de uma inquietação ${ }^{10}$ por parte dele [o estudante] sem limite de espaço e tempo dos sujeitos. Além de, analisar os dados para articulação e aprofundamento do estudo com as informações escritas no diário de bordo.

\section{Resultados e discussão - A Percepção dos futuros professores pedagogos}

Ao analisar os dados coletados percebeu-se que ao longo da formação dos professores iniciantes utilizando a sequência de atividades para apropriação do uso de diversas ferramentas eles [acadêmicos] transitaram entre a gênese pessoal e profissional. Ao passar de uma ferramenta de uso pessoal como o WhatsApp para o app Box Island, ou vice-versa, notou-se nos discursos entre os sujeitos e ações sobre os artefatos diferentes esquemas de utilização construídas por eles [sujeitos].

Iniciando a análise pela ferramenta por aspecto de uso pessoal com intencionalidade pedagógica, o WhatsApp foi um meio em que os sujeitos mais trocaram informações e conhecimentos para desenvolver as atividades iniciadas em sala de aula utilizando ferramentas para o uso profissional, tais como: app Box Island, app Quiver, app Google Documentos, app Google Sala de Aula, App LightBot entre outros.

O gráfico 1 apresenta o total de mensagens recebidas e enviadas entre os sujeitos e professor. Nesse sentido, destaca-se alguns achados no estudo: o S1 têm mais facilidade para o uso de tecnologia para o uso pessoal e emprega essas habilidades no âmbito profissional; S2 têm mais dificuldade para o uso de tecnologia e aprende as possibilidades e os limites das ferramentas do seu artefato de uso pessoal, porém, oportuniza que o S1 possa, também, instrumentalizar-se com as diferentes ferramentas no decorrer das sequências de atividades.

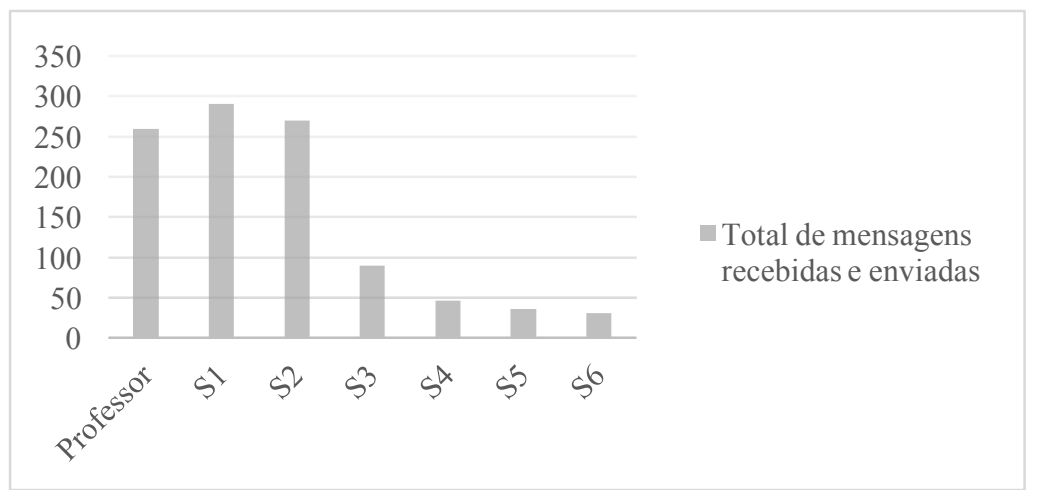

Gráfico 1 - Total de mensagens trocadas entre os sujeitos e o professor

Em relação a experiência no uso de tecnologias digitais para o uso pessoal, os acadêmicos destacaram:

S6 - Não realizei nenhum curso complementar.

S3 - Está sendo muito boa, porém as vezes eu não tenho os recursos necessários instalados para tal artefato.

\footnotetext{
${ }^{9}$ Entende-se artefato como hardware e/ou software/apps.

${ }^{10}$ Entende-se por inquietação uma determinada preocupação por parte do estudante para resolver um problema, tais como: tirar dúvidas de uma tarefa, buscar uma informação na plataforma, entender o funcionamento de uma ferramenta entre outros.
} 
S4 - Percebo mudanças significativas na tecnologia digital, em pouco tempo. É fundamental a formação continuada para nossa profissão.

S2 - Muitas dificuldades, por ser um universo abrangente.

S1 - Aprendi o básico antes da faculdade. Porém em uma das cadeiras que estou cursando, de tecnologias, tenho aprendido muito mais do que no curso que fiz quando adolescente.

S5 - Experimental.

Com relação ao uso de tecnologias em geral os sujeitos consideram-se usuário que desenvolveu habilidades em diferentes níveis de proficiência, tais como: mandar uma mensagem via WhatsApp, tirar foto do smartphone entre outros.
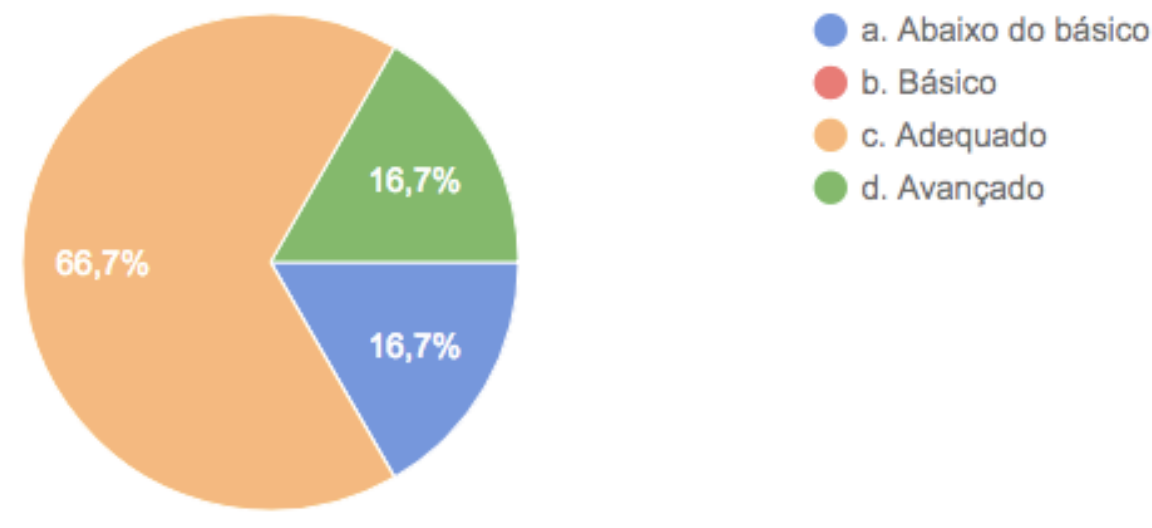

Figura 1 - Percepção dos sujeitos em relação aos níveis de proficiência tecnológica para o uso pessoal.

Para facilitar a aprendizagem e compartilhar experiências ao final do experimento com um dos aplicativos educacionais o professor sugeriu que o grupo se reunisse para reflexão [artefato] sobre as impressões de cada sujeito e em sintonia com cada uma das fases do artefato. Em relação ao uso do artefato pessoal do tipo smartphone o sujeito 6 destacou: "Bom! É pratico, pois, as vezes os aplicativos não entram, ou não aparece tudo na tela ou tem aplicativos que não conseguimos baixar para uso acadêmico não é muito bom, para uso pessoal é ótimo pois podemos fazer tudo com agilidade.". É relevante notar que o contexto massivo dos artefatos para o uso pessoal possibilitou aos futuros professores articular o uso profissional (educacional) devido a aproximação das funcionalidades entre os artefatos usados pela atual geração de crianças e jovens. Logo, é imprescindível a reflexão para o uso de tecnologias na formação e prática dos professores considerando o fenômeno da ubiquidade da informação no contexto educacional ${ }^{11}$.

Ao longo da observação deste estudo percebeu-se na expressão facial (sorrisos, risos e gargalhadas) dos estudantes durante a atividade final do app Box Island ${ }^{12}$ que o sentimento do grupo de aprender mais sem precisar de um esforço intenso para a apropriação das ferramentas e com fortes indícios que os sujeitos se apropriaram das ferramentas em diferentes níveis de consciência ${ }^{13}$ para o uso profissional. Destaca-se aqui que ao utilizar diferentes ferramentas que possibilitaram aos sujeitos o acesso [as ferramentas] sem limite de tempo e espaço devido ao fenômeno da ubiquidade oportunizou-os: a aprender de acordo com as suas preferências, processo individual de aprendizagem (mentalidade do sujeito para conectar novas com formas de aprender e ensinar), habilidades tecnológicas, experiência de vida pessoal e acadêmica e, o tempo

\footnotetext{
${ }^{11}$ Ver Valletta (2016).

${ }^{12}$ Foi explorado na aula presencial e nos espaços (casa, trabalho e faculdade) e tempos de cada sujeito.

${ }^{13}$ Ver Ken Wilber (2007). Wilber, K. Psicologia Integral. Editora Cultrix.
} 
dedicado aos estudos por cada sujeito propiciou a eles [os sujeitos] apropriar-se delas [as ferramentas] em diferentes níveis de consciência e esforço individual ou coletivo ${ }^{14}$.

\begin{tabular}{|c|c|c|}
\hline Data e Hora & Mensagem $^{15}$ & $\begin{array}{l}\text { Contextualização e breve análise do fragmento }{ }^{16} \text { dos } \\
\text { dados }\end{array}$ \\
\hline $\begin{array}{l}{[02 / 03 / 2018} \\
20: 17: 55]\end{array}$ & 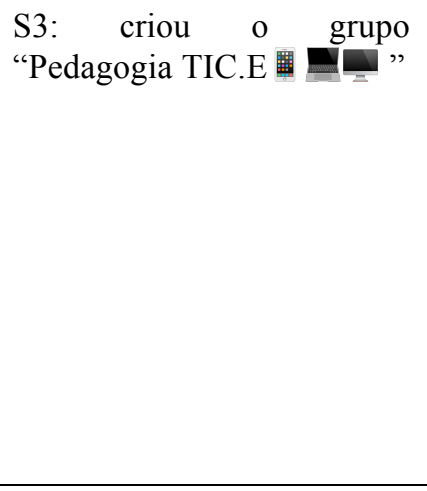 & $\begin{array}{l}\text { A professora aproveitou o engajamento dos estudantes e } \\
\text { a discussão em aula sobre a evolução das mídias e os } \\
\text { sistemas de informação e, permitiu que um dos } \\
\text { estudantes criasse o grupo para comunicação } \\
\text { emergencial e realização de estudos sob o a } \\
\text { intencionalidade pedagógica por parte do professor para } \\
\text { o uso de ferramentas de comunicação instantânea. } \\
\text { Realizou um contrato pedagógico com a turma para que, } \\
\text { na dúvida de alguma ferramenta pedissem auxílio aos } \\
\text { colegas. Caso ninguém conseguisse resolver a dúvida a } \\
\text { professora realizaria a mediação do diálogo entre os } \\
\text { participantes do grupo. }\end{array}$ \\
\hline $\begin{array}{l}{[06 / 03 / 2018} \\
21: 23: 20]\end{array}$ & $\begin{array}{l}\text { S2: Estou fazendo estagio no } \\
\text { sábado e chego em casa } \\
23: 45 \text { e tenho que levantar } \\
5: 15 \text { para voltar as } 8: 00 \text { e } \\
\text { depois retorno 13:15 como } \\
\text { vou fazer? }\end{array}$ & $\begin{array}{l}\text { A estudante preocupa-se com a organização pessoal para } \\
\text { realizar as atividades. Nota-se que é uma terça-feira e } \\
\text { não é dia da aula na universidade. O professor sugere } \\
\text { que ela pense sobre o problema para uma possível } \\
\text { solução. }\end{array}$ \\
\hline $\begin{array}{l}{[09 / 03 / 2018} \\
10: 19: 30]\end{array}$ & $\begin{array}{l}\text { S4: } \\
\text { http://www.institutonatura.o } \\
\text { rg.br/professores-podem- } \\
\text { fazer-ead-gratuito-sobre- } \\
\text { tecnologia-e-curriculo-com- } \\
\text { certificacao-do- } \\
\text { mec/?utm_source=facebook } \\
\text { \&utm_medium=post- } \\
\text { ad\&utm_campaign=P-C03- } \\
\text { 26fev-Escola-digital }\end{array}$ & $\begin{array}{l}\text { Numa sexta-feira pela manhã o S4 compartilha uma } \\
\text { matéria interessante sobre um curso EAD gratuito e } \\
\text { certificado pelo MEC. S1 sinaliza interesse postando } \\
\text { alguns emotions. }\end{array}$ \\
\hline $\begin{array}{l}{[09 / 03 / 2018} \\
23: 47: 56] \\
{[10 / 03 / 2018} \\
00: 03: 05]\end{array}$ & $\begin{array}{l}\text { S6: Porto Alegre } \\
\text { S5: Caxias do Sul }\end{array}$ & $\begin{array}{l}\text { Ao chegar em suas respectivas casas S6 e S6 } \\
\text { manifestam-se no grupo escolhendo as cidades que irão } \\
\text { investigar sobre o projeto UCA - assunto que fora } \\
\text { discutido em sala de aula (horas atrás). }\end{array}$ \\
\hline $\begin{array}{l}{[11 / 03 / 2018} \\
12: 41: 59] \\
{[11 / 03 / 2018} \\
13: 14: 25]\end{array}$ & $\begin{array}{l}\text { S3: Nossa ela criou uma } \\
\text { plataforma } \\
\text { S3: Profe qual o nome } \\
\begin{array}{l}\text { daquele joguinho pra } \\
\text { baixar? }\end{array}\end{array}$ & $\begin{array}{l}\text { A professora cria uma turma no Sala de Aula do } \\
\text { GoogleClassroom }{ }^{17} \text { para compartilhar os materiais, pois } \\
\text { está sem acesso ao Moodle. O objetivo é que eles não se } \\
\text { percam nos processos de aprendizagem. S3 fica } \\
\text { impressionado com a criação de um espaço virtual de } \\
\text { forma rápida para organizar os conteúdos e quer saber o }\end{array}$ \\
\hline
\end{tabular}

"Sob a perspectiva de Lévy (1999). Lévy, P. Cibercultura. Editora 34.

${ }^{15}$ As mensagens enviadas e recebidas foram transcritas na íntegra.

${ }^{16}$ Devido ao volume dos dados coletados retirou-se alguns fragmentos dos textos para contextualizar os eventos na troca de mensagens sobre o assunto destacado.

${ }^{17}$ O Google Sala de Aula é um aplicativo que funciona em qualquer sistema operacional. Pode-se usar nos computadores ou dispositivos móveis. Foi desenvolvido por professores e estudantes e tem como objetivo conectá-los [professores e estudantes] dentro e fora da escola, dinamizar o tempo e impressões de papel, criar turmas com autonomia, distribuir tarefas, comunicar e organizar o ambiente de acordo com as preferências do professor. Disponível em: https:/itunes.apple.com/br/app/googleclassroom/id924620788?mt=8 - Acesso em mai. de 2018. 


\begin{tabular}{|c|c|c|}
\hline $\begin{array}{l}{[12 / 03 / 2018} \\
23: 32: 32] \\
{[15 / 03 / 2018} \\
00: 25: 10]\end{array}$ & 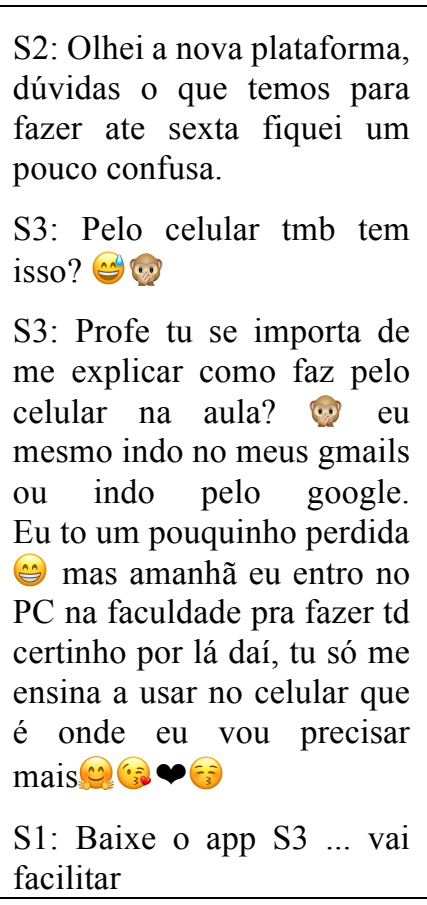 & $\begin{array}{l}\text { nome do app Box Island para aprofundamento das } \\
\text { possibilidades pedagógicas do jogo. S2 tem dúvidas na } \\
\text { interface da nova ferramenta, pois é diferente da que } \\
\text { costuma utilizar (Moodle). S3 tem a preferência de usá- } \\
\text { la [a ferramenta] no seu dispositivo pessoal e S1 ajuda a } \\
\text { colega S3 orientando-a como baixar no celular. A aula } \\
\text { presencial é dialogada. Utilizou-se um tempo para tirar } \\
\text { dúvidas entre os colegas e o professor. }\end{array}$ \\
\hline $\begin{array}{l}{[16 / 03 / 2018} \\
21: 26: 58]\end{array}$ & S4: <envio de imagens $>$ & $\begin{array}{l}\text { S4 utiliza o WhatsApp para enviar o nome dos times } \\
\text { formados durante a aula. }\end{array}$ \\
\hline $\begin{array}{l}{[17 / 03 / 2018} \\
09: 55: 31]\end{array}$ & $\begin{array}{l}\text { S1: Peço desculpas caso } \\
\text { houver algum erro de } \\
\text { português. Pois estou } \\
\text { digitando no celular.. e essa } \\
\text { "máquina " insiste em achar } \\
\text { que sabe o que está } \\
\text { sugerindo de palavras. }\end{array}$ & $\begin{array}{l}\text { A professora aproveita o diálogo para conversar sobre o } \\
\text { conceito de inteligência artificial e reforça a importância } \\
\text { de desenvolvermos o pensamento crítico em relação as } \\
\text { informações que lemos e compartilhamos no } \\
\text { ciberespaço. Uma oportunidade para desenvolver uma } \\
\text { atividade e apresentar outra ferramenta, o Dino, que } \\
\text { utiliza a tecnologia Watson da IBM. Além de discutir } \\
\text { sobre Cogntive Toys. }\end{array}$ \\
\hline $\begin{array}{l}{[17 / 03 / 2018} \\
10: 40: 53]\end{array}$ & $\begin{array}{l}\text { S2: Prof colegas. Digitei no } \\
\text { word. Agora não consigo } \\
\text { enviar preciso de ajuda }\end{array}$ & $\begin{array}{l}\mathrm{S} 2 \text { refere-se ao diário de bordo. O sujeito tem } \\
\text { dificuldade de copiar o texto da ferramenta que utiliza e } \\
\text { colar no espaço em branco do formulário do diário de } \\
\text { bordo. Ao longo da troca de mensagens os colegas } \\
\text { ajudam na resolução do problema. Devido a prática de } \\
\text { uso semanal da ferramenta Formulários não têm mais } \\
\text { dúvida de utilizá-la. }\end{array}$ \\
\hline $\begin{array}{l}{[17 / 03 / 2018} \\
19: 37: 18]\end{array}$ & $\begin{array}{l}\text { S3: Profe mas tu conseguiu } \\
\text { ler o que eu mandei do box } \\
\text { Island né? Só n ta marcado } \\
\text { como concluído isso? }\end{array}$ & $\begin{array}{l}\text { Devido ao processo de apropriação da ferramenta } \\
\text { Google Sala de Aula S3 enviou o formulário, porém, } \\
\text { esqueceu de clicar como "tarefa concluída". }\end{array}$ \\
\hline $\begin{array}{l}{[18 / 03 / 2018} \\
17: 21: 08]\end{array}$ & $\begin{array}{l}\text { S5: Não consegui abrir o } \\
\text { jogo!!! }\end{array}$ & $\begin{array}{l}\text { S5 tinha compromisso pessoal e saiu no horário do } \\
\text { intervalo, logo, não participou da discussão dos } \\
\text { processos mentais de como selecionar e buscar a } \\
\text { ferramenta nos meios digitais. Foi discutido que há } \\
\text { diferentes "lojas online" que disponibilizam os apps } \\
\text { para diferentes sistemas operacionais. Os colegas } \\
\text { enviaram um print da tela, no entanto, para S5 foi } \\
\text { necessário discutir na aula presencial para compreender } \\
\text { como buscar os recursos. }\end{array}$ \\
\hline
\end{tabular}




\begin{tabular}{|c|c|c|}
\hline $\begin{array}{l}{[24 / 03 / 2018} \\
08: 01: 07]\end{array}$ & $\begin{array}{l}\text { S1: Vocês conseguiram } \\
\text { enviar o diário de bordo? }\end{array}$ & $\begin{array}{l}\text { S4 e S5 afirmam que conseguiram enviar na noite } \\
\text { anterior e que a S1 está no link errado da tarefa. Nesse } \\
\text { sentido, nota-se a apropriação da localização das } \\
\text { ferramentas em detrimento da interface do Google Sala } \\
\text { de Aula. }\end{array}$ \\
\hline $\begin{array}{l}{[21 / 04 / 2018} \\
10: 43: 32]\end{array}$ & $\begin{array}{l}\text { S5: Prof vou te mandar pelo } \\
\text { WhatsApp o que consegui } \\
\text { fazer mas não sei como } \\
\text { salvar }\end{array}$ & $\begin{array}{l}\text { Esta tarefa propõe a leitura de três operações mentais } \\
\text { que os sujeitos deveriam fazer para concluir a tarefa. } \\
\text { Porém, todos realizaram uma leitura flutuante das } \\
\text { orientações da atividade provocando o não } \\
\text { entendimento da tarefa de forma reflexiva, ou seja, } \\
\text { realizou a atividade sem esforço cognitivo. S5 e outros } \\
\text { colegas enviaram as imagens do mapa mental produzido } \\
\text { no aplicativo que eles selecionaram, porém, a tarefa } 3 \\
\text { solicitava que o estudante deveria elaborar um mapa } \\
\text { mental no papel, tirar uma foto e compartilhar no grupo } \\
\text { de WhatsApp. Na aula de } 04 \text { de maio foi lida as } \\
\text { orientações didáticas em voz alta e percebeu-se nas } \\
\text { conversas que os estudantes não perceberam que no } \\
\text { comando solicitava o uso do papel e não do aplicativo. }\end{array}$ \\
\hline $\begin{array}{l}{[30 / 04 / 2018} \\
22: 52: 26] \\
{[30 / 04 / 2018} \\
22: 57: 39] \\
{[30 / 04 / 2018} \\
22: 57: 51]\end{array}$ & $\begin{array}{l}\text { S1: Alguém lembra o nome } \\
\text { do site para fazer o mapa } \\
\text { mental? } \\
\text { S3: Sobem? } \\
\text { S3: Sobek?* }\end{array}$ & $\begin{array}{l}\text { A aula sobre ferramentas para criar mapas mentais } \\
\text { ocorreu há duas semanas atrás. Porém, os estudantes } \\
\text { continuam se apropriando das ferramentas em } \\
\text { decorrência do seu tempo de aprendizagem em qualquer } \\
\text { espaço. O contexto da ubiquidade possibilita os sujeitos } \\
\text { buscar informações em qualquer horário do dia, } \\
\text { oportunizando-os a aprender em qualquer lugar e de } \\
\text { acordo com o seu ritmo. }\end{array}$ \\
\hline
\end{tabular}

Quadro 1 - Síntese do número total de mensagens recebidas e enviadas entre os sujeitos que interagiram no grupo de Whats App - 02/03/18 a 05/05/2018.

Tendo-se as sequências de atividades desenvolvidas nos espaços presenciais e virtuais, há indícios de que os estudantes compreenderam os objetivos de aprendizagem para o uso de tecnologia na sala de aula e foram se apropriando das ferramentas à medida em que as conexões foram articuladas a teoria, a prática de uso e no momento em que foram desafiadas a explorá-las [as ferramentas] para executar algum tipo de tarefa diferentes operações mentais provocadas pelo uso de diferentes possibilidades e intencionalidade pedagógica por parte do professor.

Pode-se inferir que o engajamento entre os estudantes é forte perante a oportunidade de se proporcionar aulas dinâmicas que utilizem ferramentas em que eles [os sujeitos] possam revisitar em qualquer espaço e tempo - fenômeno advindo da ubiquidade. A ubiquidade e a gênese instrumental articuladas entre si provoca um diálogo contemporâneo devido aos diferentes tipos de ferramentas que os professores se apropriam para apoio na sequência de atividades na sala de aula e a facilidade propiciada pelo fenômeno da ubiquidade - busca por informação de conteúdos ou ferramentas para realizar alguma tarefa.

\section{Considerações finais}

As ferramentas contemporâneas para apoio ao trabalho pedagógico do professor na escola mudaram e as possibilidades e os desafios são multifacetados pela tecnologia do momento. A ubiquidade da informação disponibilizada pela Internet e seus serviços por meio de ferramentas de fácil acesso propiciou desafios entre os estudantes, 
professores e famílias que buscam e selecionam informação a qualquer tempo e ambiente. Ampliando e estendendo a aprendizagem entre eles [estudantes e professores] dos espaços formais para os espaços não-formais. A interação entre os pares e a aproximação ao contexto da realidade local para a formação dos futuros professores traz a complexidade do mundo para a escola. Os dispositivos móveis permitem a interação em qualquer lugar e a qualquer momento facilitando o processo de aprendizagem dos sujeitos que aprendem e ensinam.

Entende-se que a infraestrutura de uma organização educacional é necessária para oportunizar a formação destes futuros profissionais, porém, os dispositivos pessoais é um exemplo de que é possível instrumentalizá-los para uma didática que rompa a cultura predominante do método tradicional de ensino. E dominar a técnica pode, talvez, permitir experiências que possam promover a inovação e a mudança no paradigma de ensinar e aprender com as tecnologias do momento.

\section{Referências Bibliográficas}

Alencar, G., dos Santos Pessoa, M., Santos, A. K. D. F. S., Carvalho, S., \& de Barros Lima, H. A. (2015). WhatsApp como ferramenta de apoio ao ensino. In Anais dos Workshops do Congresso Brasileiro de Informática na Educação - CBIE. v. 4, n. 1, p. 787.

Bogdan, R. C., Biklen, S. K., Alvarez, M. J., Vasco, A. B., dos Santos, S. B., \& Baptista, T. V. M. (1994). Investigação qualitativa em educação: uma introdução à teoria e aos métodos. Porto: Porto Editora.

Borges, K. S., Nichele, A. G., Menezes, C. S. (2016). Formação Continuada de Professores Através de Comunidades de Prática: um Estudo de Caso. Revista Brasileira de Informática na Educação, v. 24, n. 2.

Couto, H. H. O. M., Rezende, L. A. C. (2013). Media on Education: Teachers' Official Discourse in a Continuing Education Program. Brazilian Journal of Computers in Education, v. 21, n. 3, p. 85.

García, C. M. (1999). Formação de Professores: para uma mudança educativa. Porto: Porto Editora.

Grinkraut, M. L. (2009) Formação de professores envolvendo a prova matemática: um olhar acerca do desenvolvimento profissional. Revista do Programa de Estudos PósGraduados em Educação Matemática, v. 11, n. 2.

Lévy, P. (1999). Cibercultura. Editora 34.

Mendes, A. C., Medeiros Filho, D. A., Gimenes, I. M. S. (2015). Quem tem mais interesse pelo uso da informática na educação? Os professores mais jovens ou os mais velhos? - Um estudo correlacional. Revista Brasileira de Informática na Educação, v. 23, $n$. 2, p. 160.

Notare, M.; Basso, M. (2017). Gênese Instrumental Pessoal e Conceitos Matemáticos em Processo de Criação com o GeoGebra. Revista Novas Tecnologias na Educação, v. 2, p. 1-10.

Passos, C.L.B.; Nacarato, A. M.; Fiorentini, D.; Miskulin, R.G.S.; Grando, R. C.; Megid, M. A. B.; Freitas, M. T. M.; Melo, M. V. (2006). Desenvolvimento profissional do professor que ensina matemática: Uma meta-análise de estudos brasileiros. Quadrante Lisboa, v. 15, p. 193-219.

V. $16 \mathrm{~N}^{\mathrm{o}} 1$, julho, 2018 
Santaella, L. (2007). Linguagens líquidas na era da mobilidade. São Paulo: Paulus.

Valletta, D. (2014). Guia de Aplicativos para educação básica: uma investigação associada ao uso de tablets. Anais do XVII ENDIPE - Encontro Nacional de Didática e Prática de Ensino, Fortaleza, v.1, p. 1-12. bíqua: um modelo para o ciclo de formação continuada. Dissertação. Pontifícia Universidade Católica do Rio Grande do Sul, Porto Alegre. 107f. . (2016). Aplicativos para Tablets: Ferramentas para o pensar. Revista Novas Tecnologias na Educação, v. 14, p. 1-10.

Valletta, D., Grinkraut, M., \& Basso, M. (2017). A lógica de programação como ferramenta para o pensar: entre o concreto e o virtual. In: Anais do Workshop de Informática na Escola. v. 23, n. 1.p. 785.

Weiser, M. (1991). The Computer for the 21st Century, Scientific American Ubicomp, v. 265 , n. 3 , p. 66-75. 